\title{
APLICACIONES DE LA INTELIGENCIA EMOCIONAL
}

Christian Platero Ibañez. Universidad de Granada

\section{RESUMEN}

El objetivo de este artículo es desarrollar la importancia de la inteligencia emocional en la actualidad dentro de diferentes ámbitos como bien son la escuela o la educación familiar y a su vez indagar más profundamente en debates tales como la relación entre inteligencia emocional y el género, o la depresión y la felicidad en relación con el control de las emociones.

A lo largo del artículo expondré mis ideas sobre la inteligencia emocional, basándome en investigaciones realizadas por diversos autores y aportando mi juicio de valor sobre la importancia en la actualidad de una correcta educación emocional.

PALABRAS CLAVE: Inteligencia, Socialización, Adaptación del estudiante.

\section{INTRODUCCIÓN}

El término "inteligencia emocional" comenzó a tomar relevancia a partir de los años 90 gracias a autores como Peter Salovey, John Mayer o Daniel Goleman que difundieron la importancia de esta en la vida del ser humano. En este momento, se introdujeron dentro del término aquellas cualidades emocionales consideradas como importantes: La empatía, expresión y comprensión de sentimientos, la simpatía, la persistencia o la cordialidad eran algunas de ellas.

La inteligencia emocional (IE) ha tomado una gran importancia dentro de la sociedad actual. Desde las primeras investigaciones realizadas en España, se observa un crecimiento continuo de la preocupación por el tema a tratar. Es por ello que, de forma concisa, realizaré un repaso sobre la inteligencia emocional y sus aspectos más discutidos.

La IE no se centra en la inteligencia propia de cada sujeto (intelecto) sino va mas dirigida a las características de la personalidad (capacidades sociales y emocionales). Se defiende que, tener un CE (coeficiente emocional) elevado puede ser más importante para tener éxito en la vida que tener un $\mathrm{Cl}$ (coeficiente intelectual) elevado.

La discusión actual sobre la IE se centra en el planteamiento por parte de Mayer y Salovey (2007) y su modelo centrado en 4 habilidades emocionales básicas (La habilidad para percibir, expresar y valorar emociones con exactitud; la habilidad para acceder y/o generar sentimientos que faciliten el pensamiento; la habilidad para comprender emociones y el conocimiento emocional y la habilidad para regular las emociones promoviendo un crecimiento emocional e intelectual) y aquellos modelos basados en rasgos de la personalidad, defendidos por. Hoy en día, la complementariedad de estos modelos o la contraposición sigue discutiéndose.

A lo largo del artículo postularé diversos ámbitos donde se podrá ver la inclinación hacia un modelo, hacia otro o el trabajo conjunto de ambos. 
Goleman (2009) ha sido un pilar importante dentro de la inteligencia emocional. Entre otros afirma que, se puede observar la poca influencia del intelecto para conseguir el éxito $(20 \%)$ dejando un $80 \%$ a otro tipo de variables como por ejemplo la IE. De este modo, controlando la angustia, la empatía, el empeño frente a la frustración o la confianza, se puede alcanzar unos niveles de éxito óptimo, siendo "estímulos ideales para el éxito" (Goleman, 2009).

\section{DESARROLLO}

La gran mayoría de los científicos-as, están de acuerdo en establecer una serie de emociones básicas presentes en todos los seres vivos como el amor, el miedo, el dolor, el odio o la culpa. A partir de aquí se pueden abarcar diferentes grados emocionales siendo los humanos los capaces de interpretar e identificar una mayor variedad de estas.

\section{Inteligencia emocional en el entorno familiar}

La utilización de la IE en distintos ámbitos, da lugar a hablar de su importancia para educar a los niños y niñas.

Por norma general, los niños presentan un intento repetitivo para conseguir el éxito, con un gran empeño para lograr sus metas. Hoy en día, se cree que, muchos problemas de la infancia pueden explicarse por los cambios sociales, en este caso, las emociones pueden tratar de solucionarlos.

Diferentes estudios (Shapiro 1997) organizan la manera de educar a los niños en tres formas distintas: De forma autoritaria donde los padres tienden a desalentar a los niños a expresar sus opiniones y sentimientos; de forma permisiva caracterizada por aceptar las ideas del niño pero sin poner metas muy claras a sus hijos ni límites ante sus acciones; y de una forma autorizada donde se logra equilibrar límites claros con un ambiente estimulante en el hogar.

\section{El/la niño niña y sus emociones}

Los-as niños-as pueden rodearse de emociones positivas o negativas, y todo su entorno debe procurar conseguir las primeramente mencionadas.

La atención positiva genera en el niño-a una autoconfianza y optimismo para afrontar todos los retos que aparecen en su vida. Si les ayudamos a mostrar empatía hacia los demás, obtendremos unos logros mayores tanto en la escuela como en su futuro laboral, fortaleciendo entre otras cosas, la sinceridad.

Cabe destacar que la mayoría de los estudios, no muestran diferencias significativas en las conductas empáticas de niños y niñas (Rey, y Extremera. 2012). En cuanto al resto de emociones, si se aprecian diferencias de género que desarrollare más adelante.

Uno de los estados emocionales a los que se puede llegar a través de las emociones positivas es la felicidad. La correcta utilización de las emociones positivas y por consiguiente, la buena utilización y control de la IE, ayudan a conseguir una mejora personal y social en el sujeto y la sociedad, evitando de este modo conductas que podemos denominar como de riesgo y ayudando a mejorar y optimizar las relaciones 
sociales. Toda esta correcta utilización de nuestras emociones, va inevitablemente ligada a nuestra felicidad en la vida diaria (Fernandez-Berrocal y Extremera-Pacheco 2009).

Es importante destacar que, hasta el momento se afirma que de manera general, una sociedad más feliz esta instaurada sobre unas emociones positivas y de ahí el empeño por continuar las investigaciones en este rumbo (Maritza y Sanhueza 2012). Como toda teoría, nos encontramos con la parte debatiente la cual considera que la felicidad, estará determinada por tres aspectos: los genes causantes de reflejar las características de la personalidad; las circunstancias sociodemográficas y las actividades intencionales en las que cada individuo se implica de forma voluntaria.

Al igual que emociones positivas, pueden aparecer emociones negativas, tales como la vergüenza o la culpa. Estas pueden estar presentes en momentos determinados a lo largo de la vida.

La culpa puede ser neurótica, donde uno se castiga a sí mismo por razones injustificadas e irracionales, o culpa interpersonal, que surge del interés por la opinión del otro, y sirve para reducir la autocrítica y mejorar las relaciones personales de un niño-a. Esta última también es conocida como conciencia y es la manera más poderosa para controlar la conducta de los niños.

Es cierto que algunas emociones negativas como el miedo, el castigo, la vergüenza o la culpa pueden ayudar y motivar al niño-a a aprender y desarrollar conductas más adecuadas tras un previo aprendizaje y razonamiento, pero estas mismas, pueden desencadenar en un estado de depresión.

Según diversos estudios (Fernandez-Berrocal, Extremera y Ramos Diaz 2003), los momentos o estados de depresión pueden generarse por una mala regulación de las emociones. Es por ello que una buena instrucción y aprendizaje emocional, junto con un desarrollo de la inteligencia emocional positiva, puede ayudar a disminuir las posibilidades de depresión dentro de una persona consiguiendo el control de uno mismo y así poder desarrollar los aspectos positivos de las situaciones.

\section{Inteligencia emocional y el ámbito educativo}

La IE dentro del ámbito académico es otro de los puntos a destacar en mi artículo debido a su importancia en la actualidad.

Jiménez Morales y López Zafra (2009) relacionan la IE con el ajuste socio-escolar del alumnado, especialmente en lo referente al rendimiento escolar y a la aparición de estrés o ansiedad. La realización de programas centrados en habilidades de la inteligencia emocional se percibe en la actualidad como necesarios para el crecimiento personal, y como ayuda para la preparación al mundo laboral. Cada vez se defiende con mayor ímpetu que la inteligencia en el ámbito académico no es suficiente y se le da una mayor importancia a todo lo que mueve y motiva a las personas, es decir todos los aspectos emocionales y sociales. Estos aspectos deben ser tratados tanto por la familia como por la escuela para aumentar las expectativas de éxito en el futuro.

Salovey y Mayer (2007) defienden la utilización de las emociones para que el sujeto pueda solucionar los problemas que se le presenten adaptándose al medio lo más eficazmente posible. 
Para esta intervención dentro del ámbito educativo, es necesaria y oportuna la sensibilización por parte de los docentes. Mientras que en épocas anteriores no hacían especial atención a los sentimientos y las emociones, centrándose más en el control de los alumnos y alumnas, actualmente los-as educadores-as deben intentar conseguir que el alumnado consiga sentir inteligentemente, siendo conveniente la práctica de habilidades emocionales dentro del aula y el entrenamiento para, con el tiempo, ir tratando de educar la IE (Pena, Garrido y Repetto Talavera 2008)

Es importante que el/la docente no vea las emociones de forma individual sino que trate de crear un clima emocional adecuado en el colegio para recibir, interiorizar y controlar las emociones de los-as alumnos-as. Berrocal y Aranda (2008) postulan que se puede apreciar que los centros educativos y el profesorado tienen cada vez una mayor consideración a los aspectos emocionales dentro del aula para conseguir un mayor rendimiento del alumnado y un clima óptimo.

Tras esta exposición de razones, creo haber dejado clara mi postura a favor del contexto educativo para la educación emocional, pero siempre en colaboración con la familia de cada niño-a la cual desempeña un papel fundamental para que estos-as niños-as adquieran una inteligencia y valoración emocional mayor y, por consiguiente, aspiren en mayor medida al triunfo. Para conseguir estos cambios de forma sostenible, los padres deben ser en el hogar el espejo en el que se reflejen los comportamientos positivos aprendidos por el niño-a y su responsabilidad moral será fundamental en la generación de sus virtudes positivas y habilidades emocionales.

\section{Diferencias sexuales}

Por último, encuentro preciso hablar de uno de los temas más debatidos en la actualidad dentro de la inteligencia emocional, la diferenciación o no en cuanto al género.

Investigadores como Mestre, Guil y Lim (2004) coinciden en la existencia de rasgos o habilidades más desarrolladas dependiendo de sexo teniendo cada uno una serie de puntos fuertes y de puntos débiles. Se aprecia que, dependiendo del tipo de medida utilizada, aparecen diferencias de género.

En las medidas de autoinforme, los sujetos proporcionan información sobre su apreciación de su propia IE y la de una tercera persona mientras que la prueba de habilidad, los sujetos tienen que resolver determinados problemas emocionales, comparando los resultados con otros objetivos (Mayer 2001; Mayer Salovey y Caruso, 1999)

En las medidas de autoinforme hay una gran controversia ya que, aunque la mayoría de investigaciones no encuentran diferencias de género, otros encuentran una mayor capacidad de las mujeres para controlar y manejar sus emociones y las de los demás.

Por su parte, las pruebas de habilidad o ejecución, muestran claras diferencias respecto al sexo con una inteligencia emocional mayor en mujeres que en hombres. Los hombres perciben una IE mayor a la que posteriormente transmiten o realizan, y las mujeres son todo lo contrario. Es decir, las diferentes pruebas de ejecución dejan al descubierto una infravaloración de las mujeres frente a una sobrevaloración por parte de los hombres (Sánchez-Nuñez, Fernandez Berrocal, Montañes Rodriguez y Latorre-Postigo 2008; Petrides y Furnham, 2000) 
Los datos revelan que los estereotipos dificultan e impiden en cierto modo la inteligencia emocional, siendo las personas menos estereotipadas y ligadas a pensamientos sociales, las poseedoras de un mayor desarrollo de su inteligencia emocional, alejándose de este modo de los roles que, supuestamente, deben cumplir dependiendo del sexo (Aritzeta, Balluerka y Barberá 2012). La expresividad es un factor muy importante para desarrollar la IE y los hombres, en comparación con las mujeres, presentan una expresividad inferior que deben intentar trabajar.

\section{CONCLUSIÓN}

A modo de conclusión puedo garantizar y apoyar la importancia de la psicología emocional en la actualidad para lograr el éxito en la vida. Muchos científicos creen que nuestras emociones humanas han evolucionado fundamentalmente como un mecanismo de supervivencia.

Como bien adelantó Goleman y otros autores de renombre, la IE es muy importante, tanto es así que la educación en la infancia debe permanecer ligada a este término. De ahí la importancia de transmitir emociones positivas como la empatía, y tratar de evadir o aprender de las emociones negativas para poder crecer y crear una sociedad más feliz y propensa al éxito.

Entrelazada con la educación familiar, se encuentra la educación escolar donde se deben de construir espacios educativos que hagan crecer las fortalezas individuales del alumnado para su crecimiento personal y social.

Independientemente del género o la edad, la IE juega un factor importante a lo largo de la vida. Por ello es merecedora de atención, investigación, desarrollo y control, evitando así verdaderos desastres sociales y consiguiendo una sociedad más preparada para lograr el éxito individual y colectivo.

\section{REFERENCIA BIBLIOGRÁFICA}

Fernández-Berrocal, P., Extremera, N. y Ramos-Díaz, N. (2003). Inteligencia emocional y depresión. Encuentros en psicología social, 1, 251-254.

Fernández-Berrocal, P., Extremera-Pacheco, N. (2009). La inteligencia emocional y el estudio de la felicidad. Revista interuniversitaria de formación del profesorado, 66, 85108.

Fernández-Berrocal, P. y Extremera-Pacheco, N. La inteligencia emocional como una habilidad esencial en la escuela. Revista Iberoamericana de educación.

Fernández-Berrocal, P. y Ruiz-Aranda, D. (2008). La inteligencia emocional en la educación. Revista electrónica de investigación psicoeducativa. ISNN, 6, 421-436.

Gartzia, L., Aritzeta, A., Balluerka, N., Barberá, E. (2012). Inteligencia emocional y género: más alla de las diferencias sexuales. Anales de psicología, 28, 567-575.

Goleman, D. (2009). Inteligencia Emocional. Barcelona: Kairós. 
Jiménez-Morales, M. I. y López-Zafra, E. (2009). Inteligencia emocional y rendimiento escolar: estado actual de la cuestión. Revista latinoamericana de psicología, 41, 69-79.

Maritza-Espinoza, V., Sanhueza, A.O., (2012). Miedo a la muerte y su relación con la inteligencia emocional de estudiantes de enfermería de concepción. ACTA Paul Enferm, 4, 607-613.

Maye r, J. D., Caruso, D. y Salovey, P. (1999). "Emotional intelligence meets traditional standards for an intelligence". Intelligence, 27, 267-298.

Mayer, J.D. y Salovey, P. (2007). ¿Qué es inteligencia emocional? En Mestre, J.M. y Fernandez Berrocal, P. (Eds): Manual de inteligencia emocional, Madrid, Ed. Pirámide

Mestre, J. M., Guil, R. y Lim, N. (2004). Inteligencia emocional: ¿ A qué pueden deberse las diferencias respecto a la variable género? En E. Barberá, L. Mayor, M. Choliz, E. Cantón, E, Carbonell, C. Candela y C. Gómez (Eds,), Motivos emociones y procesos representacionales: De la teoría a la práctica. Valencia, ADEIT.

Pena-Garrido, M. y Repetto Talavera, E. (2008). Estado de la investigación en España sobre la inteligencia emocional en el ámbito educativo. Revista electrónica de investigación psicoeducativa, 6, 400-420.

Petrides, P. V. y Furnham, A. (2000). Gender Differences in measured and selfestimated trait emotional intelligence. Sex Roles, 449-46.

Rey, L., y Extremera, N. (2012). Inteligencia emocional percibida, felicidad y estrategias distractoras en adolescentes. Boletín de psicología,104, 87-101.

Sánchez-Nuñez, M. T., Fernandez-Berrocal, P., Montañes-Rodriguez, J. y

Latorre-Postigo, J.M. (2008). ¿Es la inteligencia emocional una cuestión de género? Socialización de las competencias emocionales en hombres y mujeres y sus implicaciones. Revista de investigación psicoeducativa, 6, 455-474.

Shapiro, L.E. (1997). La inteligencia emocional de los niños. México: Vergara editor. 